\title{
Akebia trifoliate (Thunb.) Koidz Seed Extract Inhibits the Proliferation of Human Hepatocellular Carcinoma Cell Lines via Inducing Endoplasmic Reticulum Stress
}

\author{
Wen-Li Lu, ${ }^{1}$ Hong-Yan Ren, ${ }^{1}$ Cao Liang, ${ }^{1}$ Yuan-Yuan Zhang, ${ }^{1}$ Ji Xu, ${ }^{2}$ Zhi-Qiang Pan, \\ Xiao-Mei Liu, ${ }^{1}$ Zhong-Hua $W u,{ }^{3}$ and Zhao-Qin Fang ${ }^{1}$ \\ ${ }^{1}$ College of Basic Medical Science, Shanghai University of Traditional Chinese Medicine, No. 1200, Cailun Road, \\ Shanghai 201203, China \\ ${ }^{2}$ Scientific Information Centre, Shanghai University of Traditional Chinese Medicine, No. 1200, Cailun Road, Shanghai 201203, China \\ ${ }^{3}$ Scientific \& Technology Experimental Centre, Shanghai University of Traditional Chinese Medicine, No. 1200, Cailun Road, \\ Shanghai 201203, China
}

Correspondence should be addressed to Zhao-Qin Fang; zqfang@sh163.net

Received 30 April 2014; Revised 16 July 2014; Accepted 14 August 2014; Published 20 October 2014

Academic Editor: Chong-Zhi Wang

Copyright (C) 2014 Wen-Li Lu et al. This is an open access article distributed under the Creative Commons Attribution License, which permits unrestricted use, distribution, and reproduction in any medium, provided the original work is properly cited.

\begin{abstract}
Akebia Fructus has long been used for hepatocellular carcinoma (HCC) in China, while the molecular mechanism remains obscure. Our recent work found that Akebia trifoliate (Thunb.) Koidz seed extract (ATSE) suppressed proliferation and induced endoplasmic reticulum (ER) stress in SMMC-7721. The present study aimed to throw more light on the mechanism. ER stress occurred after ATSE treatment in HepG2, HuH7, and SMMC-7721 cells, manifested as ER expansion, and SMMC-7721 was the most sensitive kind in terms of morphology. Cell viability assay showed that ATSE significantly inhibited cells proliferation. Flow cytometry analysis indicated that ATSE leads to an upward tendency of G0/G1 phase and a reduced trend of the continuous peak after G2/M phase in HepG2; ATSE promoted apoptosis in HuH7 and a notable reduction in G0/G1 phase; ATSE does not quite influence cell cycles of SMMC-7721. Western blot analysis showed an increased trend of the chosen ER stress-related proteins after different treatments but nonsignificantly; only HYOU1 and GRP78 were decreased notably by ATSE in HuH7. Affymetrix array indicated that lots of ER stress-related genes' expressions were significantly altered, and downward is the main trend. These results suggest that ATSE have anticancer potency in HCC cells via partly inducing ER stress.
\end{abstract}

\section{Introduction}

According to the Word Cancer Report from IARC (International Agency for Research on Cancer), human hepatocellular carcinoma (HCC) is the sixth most common malignant cancer throughout the world and the third in China; the cases in China are more than half of the total worldwide $[1,2]$. Surgical resection during early stages is still the dominant therapy for HCC. Unfortunately, most patients have already missed this opportunity by the time they see a doctor, and even patients who have been operated upon are at risk of recurrence, metastasis, and poor prognosis. On the other hand, most of the anticancer drugs may show severe side effects. Under these circumstances, the need of exploring new drugs in natural products, such as extracts of traditional Chinese herbs, becomes one promising alternative $[3,4]$. In fact, in China, nearly $80 \%$ percent of patients suffering from HCC have taken herbs or herbal compounds to alleviate symptoms, relieve the side effects of radiotherapy or chemotherapy, improve the quality of life, and even extend life span [5-7].

Akebia Fructus is the near-mature dried fruit of plant Akebia and belongs to Lardizabalaceae family. The family is widely distributed over East Asia including China, Japan, and Korea. Akebia Fructus has long been used for HCC in China because of its traditional function of removing blood stasis and purging hard lump; it is also called "Bayuezha" due to ripe and crack in August [8]. There are three medicinal species, including Akebia quinata (Thunb.) Decne, Akebia 
trifoliate (Thunb.) Koidz, and Akebia trifoliate (Thunb.) Koidz. var. australis (Diels.) Rehd, whichare listed in the Chinese Pharmacopoeia [9]. In some experimental studies in vivo and vitro, the water extract of the whole fruit of Akebia trifoliate, the ethanol extract of Akebia quinata seed, or the separated ingredients showed antitumor activity [10-13], while the molecular mechanism remains obscure.

Akebia Fructus is always used as a whole fruit, which is composed of the pulp and the seed. In our recent research, extracts of different parts of Akebia trifoliate (Thunb.) Koidz, including the whole fruit, the pulp, and the seed, were used to treat SMMC-7721 HCC cells, respectively, and we unexpectedly found that seed part showed the strongest effect in inhibiting malignant proliferation and inducing endoplasmic reticulum (ER) stress [14-18], whilst no reference data on ER stress currently exist. In view of this, this further study aims to prepare an Akebia trifoliate (Thunb.) Koidz seed extract (ATSE) by n-butanol and throw more light on the molecular mechanism in a panel of three HCC cell lines, HepG2, HuH7, and SMMC-7721.

\section{Material and Methods}

2.1. Chemicals and Antibodies. Ethanol, Petroleum ether, ethyl acetate, and n-butanol are all AR grade and purchased from Sinophar Chemical Reagent Co., Ltd. (Shanghai, China). Trizol, G418, and 3-(4,5-dimethylthiazol-2-yl)-2,5diphenyltetrazolium bromide (MTT) were purchased from Life Technologies (Carlsbad, CA, USA). Rabbit anti-SEC63 $(1: 800)$ polyclonal and rabbit anti-DNAJB11 (1:500) polyclonal were purchased from Sigma-Aldrich (St. Louis, MO, USA). Rabbit anti-HSP90AA1 (1:1000) was purchased from Stressgen (Enzo Life Sciences, NY, USA). Rabbit antimonoclonal HYOU1 (1:5000) was purchased from Epitomics (Abcam, CA, USA). Mouse monoclonal anti-GRP78 (1:1000), mouse monoclonal anti-HSPA9 (1:1000), and mouse monoclonal anti-GAPDH $(1: 2500)$ were purchased from Santa Cruz Biotechnology (Santa Cruz, CA, USA). The secondary antibodies HRP Goat anti-mouse IgG and HRP Donkey anti-rabbit IgG were purchased from Biolegend (San Diego, CA, USA).

2.2. Plant Material. The whole fruit of Akebia trifoliate (Thunb.) Koidz was purchased from Kangqiao Herbal Pieces Co. Ltd. (Shanghai, China) in May 2013, which was produced in Zhejiang Province and authenticated by Lihong Wu, Institute of Chinese Meteria Medica, Shanghai University of Traditional Chinese Medicine; a voucher specimen (number 130319) was deposited in the standardization lab of this institute.

2.3. Preparation of Akebia trifoliate (Thunb.) Koidz Seed Extract (ATSE). The seed was peeled off from the whole fruit and dried at $60^{\circ} \mathrm{C}$ for 24 hours; dried seed ( $800 \mathrm{~g}$ ) was smashed and soaked in $75 \%$ ethanol for 2 hours at room temperature and then extracted by $8 \mathrm{~L} 75 \%$ ethanol reflux at $80^{\circ} \mathrm{C}$ for 2 hours and filtered by gauze; the filtration residue was extracted again under the same condition; all resulting filtrations were combined and concentrated by Rotavapor
(BÜCHI Labortechnik, Switzerland) under reduced pressure; $2700 \mathrm{~mL}$ concentrated extract was obtained, followed by successive extraction with the same volume of Petroleum ether, ethyl acetate, and water-saturated n-butanol, three times in each solvent; this procedure resulted in three extracts; the nbutanol soluble extract was further concentrated by Rotary Evaporator (IKA, Germany) at $60^{\circ} \mathrm{C}(20-40 \mathrm{rpm}) ; 310 \mathrm{~mL}$ extractum was obtained and then freeze-dried to $33.26 \mathrm{~g}$ power, which is simply called ATSE in experiment. The extract yield was $4.26 \%$ (w/w). ATSE was diluted to $0.5 \mathrm{~g} / \mathrm{mL}$ by distilled water and then dissolved in the RPMI 1640 culture medium to $10 \mathrm{mg} / \mathrm{mL}$ and finally filtered through a $0.45 \mu \mathrm{m}$ filter for use.

2.4. Cell Lines and Culture. HepG2, HuH7, and SMMC-7721 cell lines were obtained from Chinese Academy of Sciences (Shanghai, China), cells were maintained in RPMI 1640 medium supplemented with $10 \%$ fetal bovine serum (FBS), $100 \mathrm{U} / \mathrm{mL}$ penicillin, and $100 \mu \mathrm{g} / \mathrm{mL}$ streptomycin. RPMI 1640 medium, Trypsin, penicillin, and streptomycin were all purchased from Hyclone (Thermo scientific, UT, USA). These cells were routinely cultured in humidified 95\% air and 5\% $\mathrm{CO}_{2}$ at $37^{\circ} \mathrm{C}$.

2.5. Cell Morphological Assessment. Cells were split and seeded in 96-well and 6-well plates, 18-24 hours after seeding, and when the confluency was about $70 \%$, G418 or ATSE was added to four different groups according to the requirement: untreated control; G418 group $(0.45 \mathrm{mg} / \mathrm{mL})$; ATSE group $(0.625 \mathrm{mg} / \mathrm{mL})$; the combination group was composed of half dose of each $(0.225 \mathrm{mg} / \mathrm{mL}$ G418 plus $0.31 \mathrm{mg} / \mathrm{mL}$ ATSE). 72 hours after treatment, cells in 96-well plates were used for MTT assay, and the cell morphology of 6-well plates was firstly examined under an inverted phase contrast microscope (Olympus CKX41, Tokyo, Japan), then for the other different assays.

2.6. Cell Viability Assay. Cell survival was assessed using an MTT assay at 72 hours after treatment; the culture medium of 96-well plate was removed and replaced with $0.5 \mathrm{mg} / \mathrm{mL}$ MTT solution. After $4 \mathrm{~h}$ incubation at $37^{\circ} \mathrm{C}$, this solution was removed and the resulting blue formazan was solubilized in $100 \mu \mathrm{L}$ DMSO; then the optical density was read at $490 \mathrm{~nm}$ using a microplate reader (BioTek Synerge 2, BioTek Instruments, VT, USA). Cell viability was expressed as a percentage of the control.

2.7. Flow Cytometry Analysis of Cell Cycle. Treatments of cells were performed according to the protocol of the PI detection kit (KeyGEN Biotech, Shanghai, China). Briefly, cells were harvested and resuspended in cold PBS at a concentration of $1 \times 10^{6}$ cells $/ \mathrm{mL}$ and then fixed by 3 times volume of cold anhydrous ethanol (final concentration is 75\%) and kept at $4^{\circ} \mathrm{C}$ for 2 hours; ethanol was then removed and resuspended in $500 \mu \mathrm{L}$ buffer $\mathrm{A}$, followed by addition of RNase A (final concentration was $0.25 \mathrm{mg} / \mathrm{mL}$ ) and $5 \mu \mathrm{L}$ PI solution, and then incubated for $30 \mathrm{~min}$ at room temperature in the dark; 
finally analysis was performed by using a Flow Cytometer (BD FACS Calibur, BD Biosciences, CA, USA).

2.8. Western Blot Analysis. Cell lysates were harvested in RIPA buffer (50 mM Tris (pH 7.4), 150 mM NaCl, 1\% NP-40, $0.5 \%$ sodium deoxycholate, and $0.1 \%$ SDS). The whole cell lysates were centrifuged at $12,000 \mathrm{rpm}$ for 15 minutes at $4^{\circ} \mathrm{C}$; then the supernatant was collected and protein concentration was measured by Pierce BCA Protein Assay Kit (Thermo scientific, UT, USA). Cell lysates $(20 \mu \mathrm{g})$ were resolving on 6-8\% SDS-PAGE followed by transfer onto $0.45 \mu \mathrm{m}$ PVDF membrane (Merk millpore, MA, USA). Subsequently, membranes were incubated with 5\% skimmed milk in TBST for $1 \mathrm{~h}$, followed by probing with the primary antibody overnight at $4^{\circ} \mathrm{C}$. After washing with TBST, the membranes were incubated for $1 \mathrm{~h}$ at room temperature with HRP-conjugated secondary antibodies; bands were visualized using BeyoECL Plus western blot detection system (Beyotime, Shanghai, China). Results of the Western blot assay reported here are representative of three experiments; glyceraldehyde-3phosphate dehydrogenase (GAPDH) was used as internal control.

2.9. Affymetrix Array. Total RNA was isolated from cells with Trizol according to manufacturer's protocol. The qualities of all RNA samples were monitored: the absorbance at $260 \mathrm{~nm}$ and $280 \mathrm{~nm}$ was measured by NanoDrop 1000 (Thermo Fisher Scientific, MA, USA) and acceptable A260/280 ratios were in the range of 1.7-2.1; the RNA 6000 Nano kit (Agilent Technologies, CA, USA) was used to detect RIN (RNA integrity number) and 28S/18S ratios by Agilent 2100 Bioanalyzer (Agilent Technologies, CA, USA); the former was approximately 9.2 and the latter were approaching $2: 1$. High-quality total RNA was used as a starting material for making total RNA/Poly-A RNA controls and was mixed using a GeneChipR Poly-A RNA Control Kit (Affymetrix, CA, USA). Then cDNA was synthesized using an Ambion WT Expression Kit (Affymetrix, CA, USA), followed by ssDNA fragmentation and labeling of fragmented ssDNA with GeneChip WT Terminal Labeling Kit (Affymetrix, CA, USA). The biotin-labeled fragmentations were hybridized to a gene chip (Affymetrix HuGene 1.1 Sense Target Array) at $48^{\circ} \mathrm{C}$ for $16 \mathrm{~h}$. Following hybridization, the chips were washed and stained in the GeneAtlas Fludic Station (Affymetrix, CA, USA). Then the arrays were put into the GeneAtlas Imaging Station (Affymetrix, CA, USA). Microarray data were analyzed by Affymetrix Expression Console (Affymetrix, CA, USA). The data were normalized using the iterative PLIER default protocol. Changes in gene expressions were analyzed and compared with untreated control and the criteria for positive fold change are greater than 1.5-fold increase or decrease.

2.10. Statistical Analysis. Data were analyzed using the IBM statistics SPSS 19.0 software. The results are presented as means \pm standard deviation (S.D.) and the comparison between groups was analyzed by one-way analysis of variance (ANOVA). A value of $P<0.05$ was considered as statistically significant. All experiments were performed for a minimum of three times.

\section{Results}

3.1. ATSE Cause Different Morphological Changes in HCC Cell Lines. The morphological changes induced by ATSE were observed. HepG 2 cells were not sensitive to $0.45 \mathrm{mg} / \mathrm{mL}$ G 418 (Figure 1(b)), while mild endoplasmic reticulum stress (see the white arrowhead) was induced by $0.625 \mathrm{mg} / \mathrm{mL}$ ATSE (Figure 1(c)); the effect of the combination of half doses of each (Figure 1(d)) was similar to that in Figure 1(c). In contrast to HepG2 cells, $0.45 \mathrm{mg} / \mathrm{mL}$ G418 caused obvious morphological changes in $\mathrm{HuH} 7$ cells, including a decreased number of cells, increased blank area, and even emergence of the apoptotic body in a couple of cells (Figure 1(f)); $0.625 \mathrm{mg} / \mathrm{mL}$ ATSE caused mild ER stress (Figure $1(\mathrm{~g})$ ); the effect of the combination group (Figure $1(\mathrm{~h})$ ) was like the overlay of Figures 1(f) and 1(g). As to SMMC-7721 cells, $0.625 \mathrm{mg} / \mathrm{mL}$ ATSE resulted in remarkable ER stress, displayed as different degree of ER expansion (Figure 1(k)); in the combination group (Figure 1(l)), since the ATSE dose was cut by half, the ER stress was comparatively lighter.

In brief, ATSE induced ER stress in these three HCC cell lines but the degree varied and it seemed that SMMC-7721 cells were the most sensitive kind.

3.2. ATSE Suppress Cell Viability in HCC Cell Lines. To assess the effect of ATSE on cell viability, MTT assay was performed. As shown in Figure 2, compared to the untreated control, cell viability decreased significantly but varied in degree: values of ATSE groups were reduced to $85.9 \%$ in HepG2, 19.1\% in $\mathrm{HuH7}$, and $91.8 \%$ in SMMC-7721 cells, respectively; besides, in G418 groups, values were reduced to $83.3 \%$ in HepG2, 3.8\% in $\mathrm{HuH7}$, and $29.6 \%$ in SMMC-7721 cells, respectively; in the combination groups, values were reduced to $70.3 \%$ in HepG2, $12.5 \%$ in $\mathrm{HuH}$, and $70.7 \%$ in SMMC-7721 cells, respectively. On the other hand, in HepG2 and HuH7 cells, ATSE and the combination groups exhibited no significant difference compared to G418, but in SMMC-7721 cells, the values of these two groups were notably higher than that of G418.

\subsection{Different Cell Cycle Influences of ATSE on HCC Cell Lines.} To figure out whether the proliferation inhibition is due to cell cycle arrest, the cell cycle analysis by Flow cytometry was performed, and these HCC cell lines showed different features as shown below.

Firstly, In HepG2 cells, at 72 hours after G418 incubation, the percentage of cells in G0/G1 phase decreased significantly to $52.9 \%$ versus $59.7 \%$ of the control (Figures $3(\mathrm{~b})$ and $3(\mathrm{~m})$ ), while the percentage of same phase for ATSE was $62.9 \%$ and slightly higher than the control, albeit nonsignificantly (Figures $3(\mathrm{c})$ and $3(\mathrm{~m})$ ), which possibly indicated various action modes between ATSE and G418 on HepG 2 cells; furthermore, it seemed that the amount of the continuous peak after G2/M phase was reduced (see black arrowheads in Figure 3(c)); this could be another aspect of ATSE (Figures 3(a) and 3(c)). An apoptotic peak appeared in the combination group and the percentage reduced to $47.5 \%$ notably (Figures $3(\mathrm{~d})$ and $3(\mathrm{~m})$ ).

In HuH7 cells (Figures 3(e) to 3(h)), 72 hours after cultivation, apoptosis occurred among all groups before G0/G1 


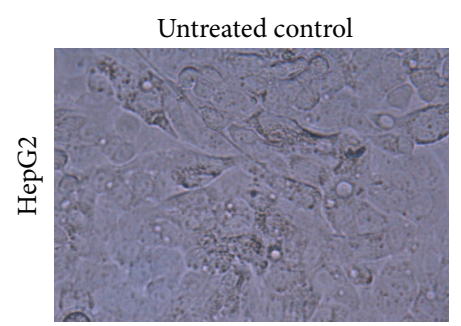

(a)

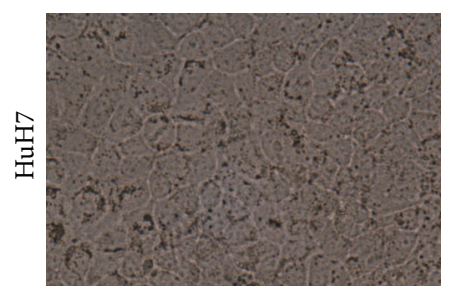

(e)

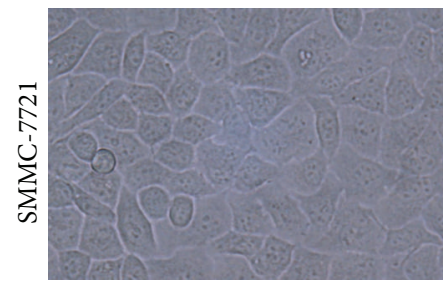

(i)

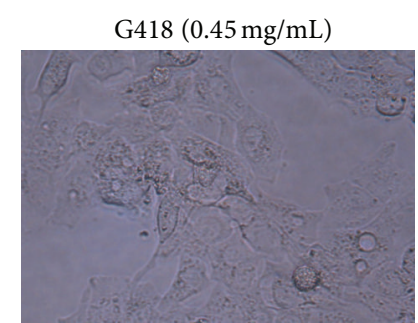

(b)

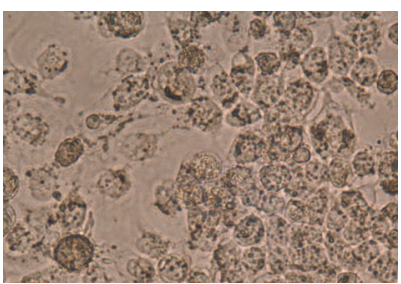

(f)

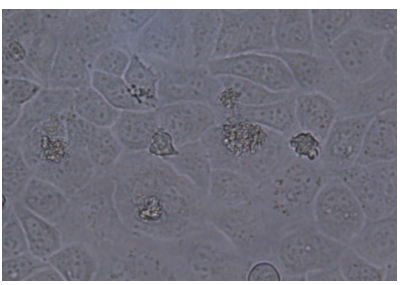

(j)

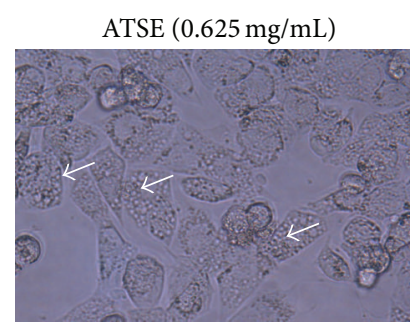

(c)

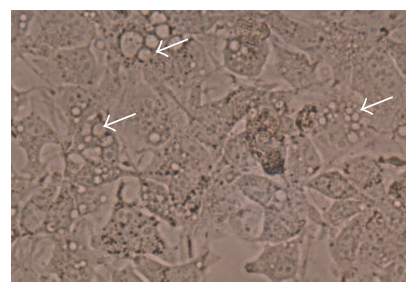

(g)

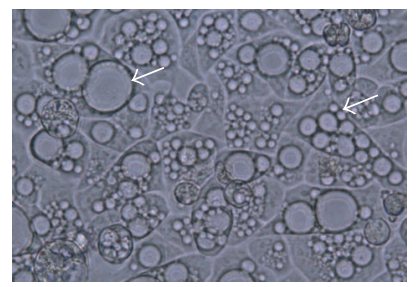

(k)

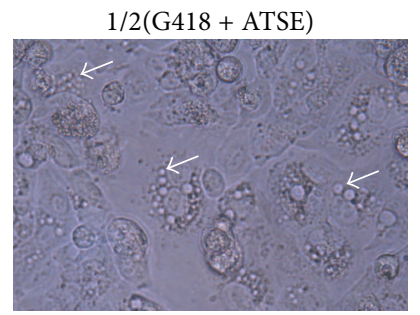

(d)

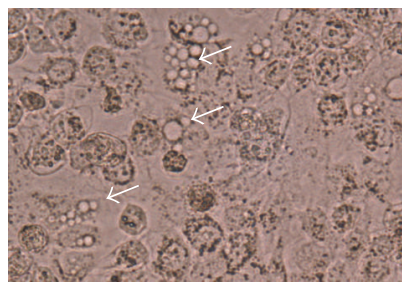

(h)

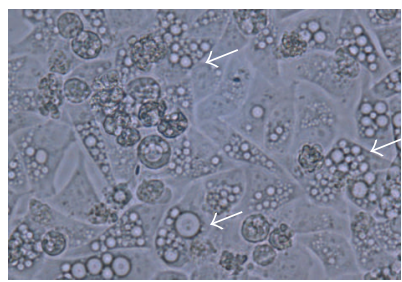

(1)

FIGURE 1: ATSE cause different morphological changes in HCC cell lines. G418 (0.45 mg/mL), ATSE: Akebia trifoliate seed extract (0.625 mg/ $\mathrm{mL}$ ), and 1/2(G418 + ATSE): a combination of half dosage of each accordingly. (a-d) Images of HepG2 cells after different treatments, (e-h) images of HuH7 cells after different treatments, and (i-1) images of SMMC-7721 cells after different treatments. White arrowhead means different degree of ER expansion within cells. These images were taken under the 400x inverted phase contrast microscope.

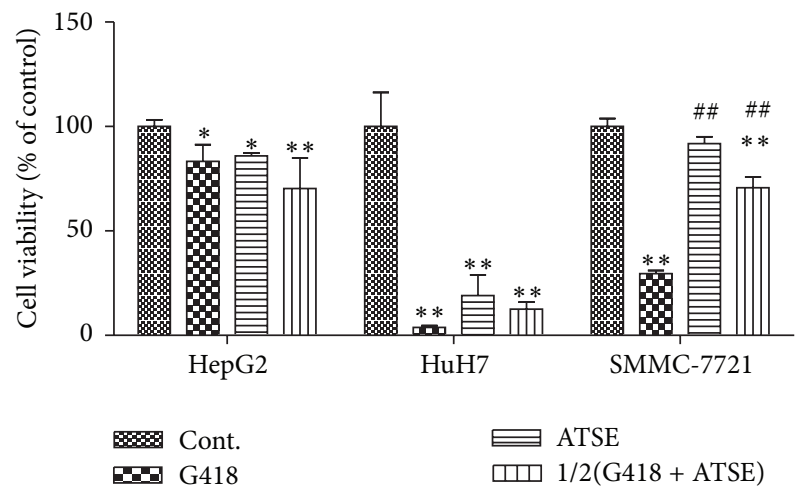

FIGURE 2: ATSE suppress cell viability in HCC cell lines. Cell viability was tested by MTT. G418 $(0.45 \mathrm{mg} / \mathrm{mL})$, ATSE: Akebia trifoliate seed extract $(0.625 \mathrm{mg} / \mathrm{mL})$, and $1 / 2(\mathrm{G} 418+$ ATSE): a combination of half dosage of each accordingly. The results are expressed as mean \pm S.D. $(n=4) .{ }^{* *} P<0.01$ and ${ }^{*} P<0.05$ (versus control group); ${ }^{\# \#} P<0.01$ and ${ }^{\#} P<0.05$ (versus G418 group).

phase, especially in ATSE group. Apoptotic body peak (see double arrowheads, Figure $3(\mathrm{~g})$ ) and apoptotic cell peak (see single arrowhead, Figure $3(\mathrm{~g})$ ) can be seen, which is typically different from the other two kinds and corresponding to MTT assay data (Figure 2). This unique feature also influences its cell cycles, including the percentage in G0/G1 phase which decreased significantly after ATSE or combined treatment, specifically $49.4 \%$ for ATSE and $57.7 \%$ for the latter, and a corresponding increasing trend in $\mathrm{S}$ phase and G2/M phase (Figures 3(g), 3(h), and 3(n)). The percentage in G0/G1 phase of G418 reduced to $62.8 \%$ but there is no statistical difference versus control group $(P>0.05$; Figures 3(f) and 3(n)).

Unlike HepG2 or HuH7, basically ATSE does not influence much cell cycles of SMMC-7721 (Figures 3(i) to 3(1)). There is no statistical difference between all groups $(P>0.05$; Figure 3(o)).

3.4. Effect of ATSE on the Protein Expression of ER Stress-Related Biomarkers. To further clarify the molecular mechanism of ATSE induced ER stress in HepG2, HuH7, and SMMC7721 cells, some ER stress-related proteins were chosen and examined by Western blot analysis. As indicated in Figure 4, compared with the untreated control, most of the proteins expressions displayed an upward tendency after different treatments, albeit nonsignificantly $(P>0.05)$. However, in $\mathrm{HuH7}$ cells, ATSE decreased the protein expression of HYOU1 and GRP78 significantly (Figures 4(a) and 4(e)). On 


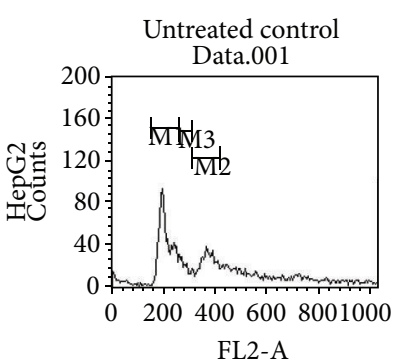

(a)

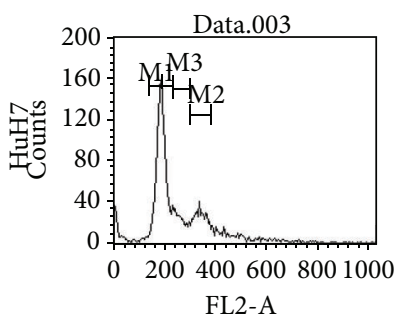

(e)

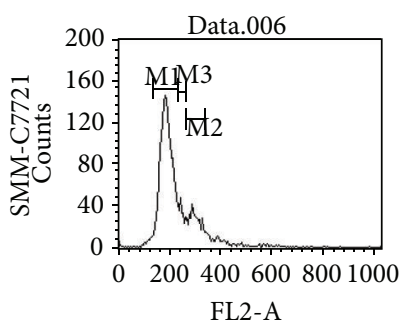

(i)

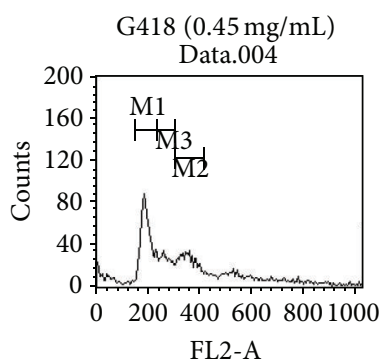

(b)

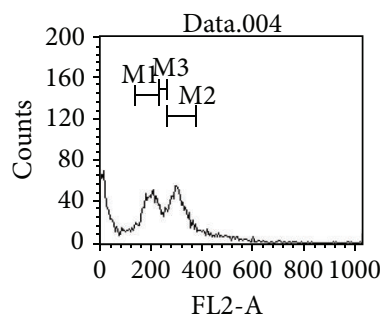

(f)

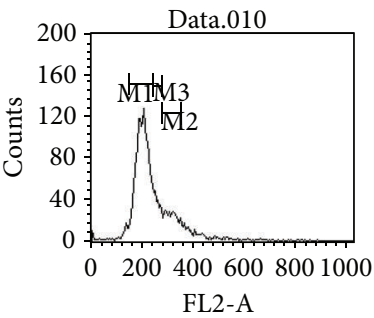

(j)

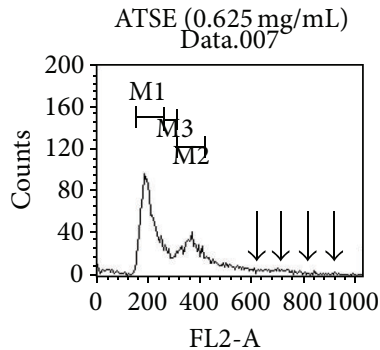

(c)

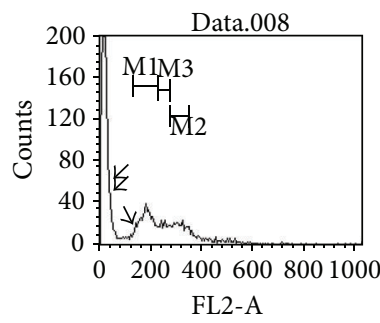

(g)

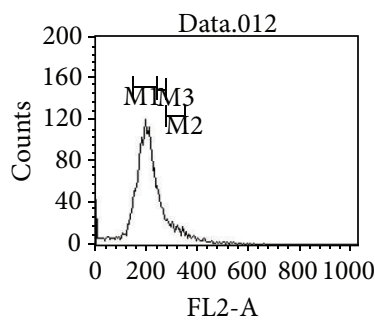

(k)

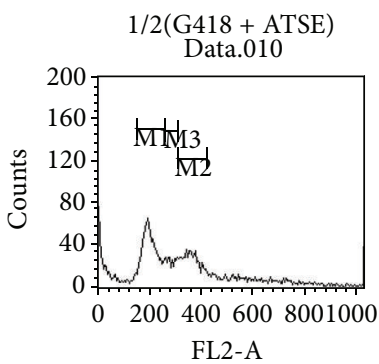

(d)

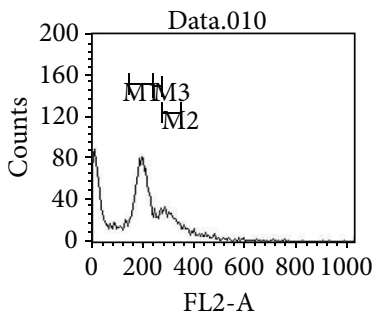

(h)

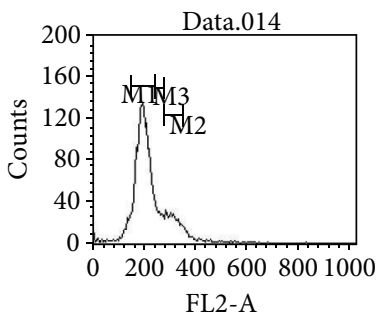

(l)

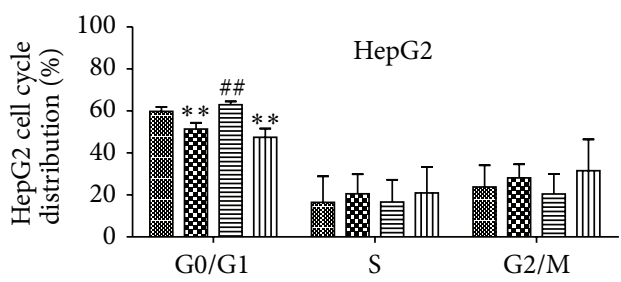

(m)

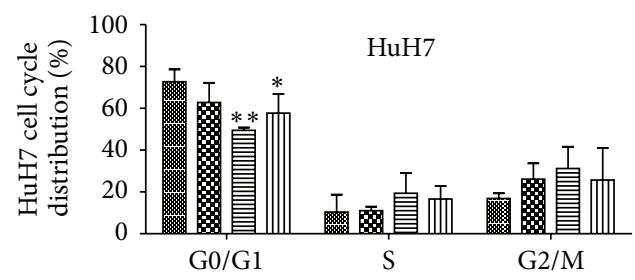

(n)

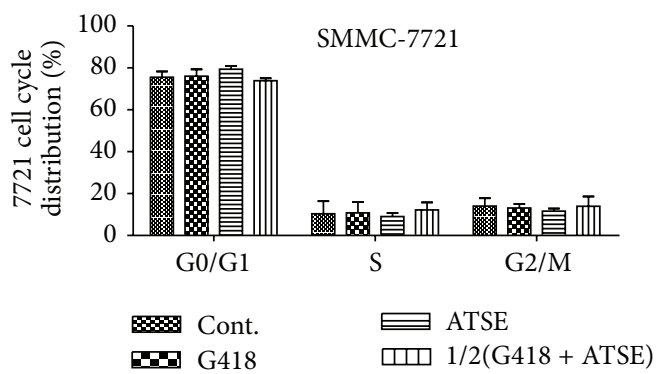

(o)

FIGURE 3: Different cell cycle influences of ATSE on HCC cell lines. Cell cycle analysis was performed by Flow Cytometry. G418 (0.45 mg/mL); ATSE: Akebia trifoliate seed extract $(0.625 \mathrm{mg} / \mathrm{mL}) ; 1 / 2(\mathrm{G} 418$ + ATSE): a combination of half dosage of each accordingly. (a-d) Images of HepG2 cells after different treatments, (e-h) images of HuH7 cells after different treatments, (i-1) images of SMMC-7721 cells after different treatments, (m) HepG2 cell cycle distribution, (n) HuH7 cell cycle distribution, and (o) SMMC-7721 cell cycle distribution. M1: G0/G1 phase, M2: G2/M phase, and M3: S phase. $(\downarrow \downarrow \downarrow \downarrow)$ continuous peak after G2/M phase after ATSE treatment, $(\downarrow \downarrow)$ apoptotic body peak, and $(\downarrow)$ apoptotic cell peak. The results are expressed as mean \pm S.D. $(n=3) .{ }^{* *} P<0.01$ and ${ }^{*} P<0.05$ (versus control group); ${ }^{\# \#} P<0.01$ and ${ }^{\#} P<0.05$ (versus G418 group). 

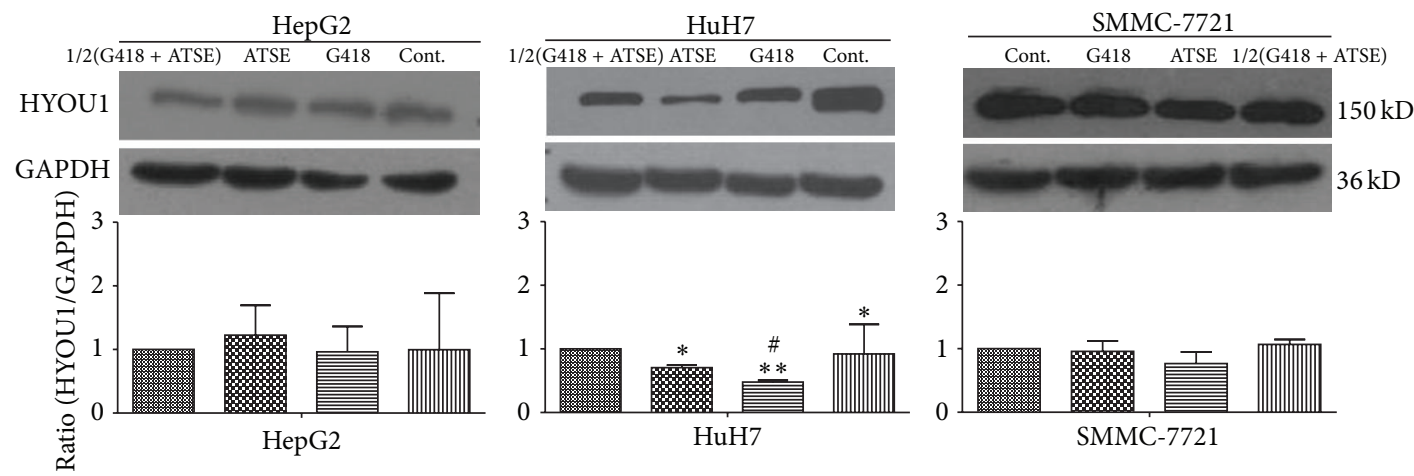

(a)
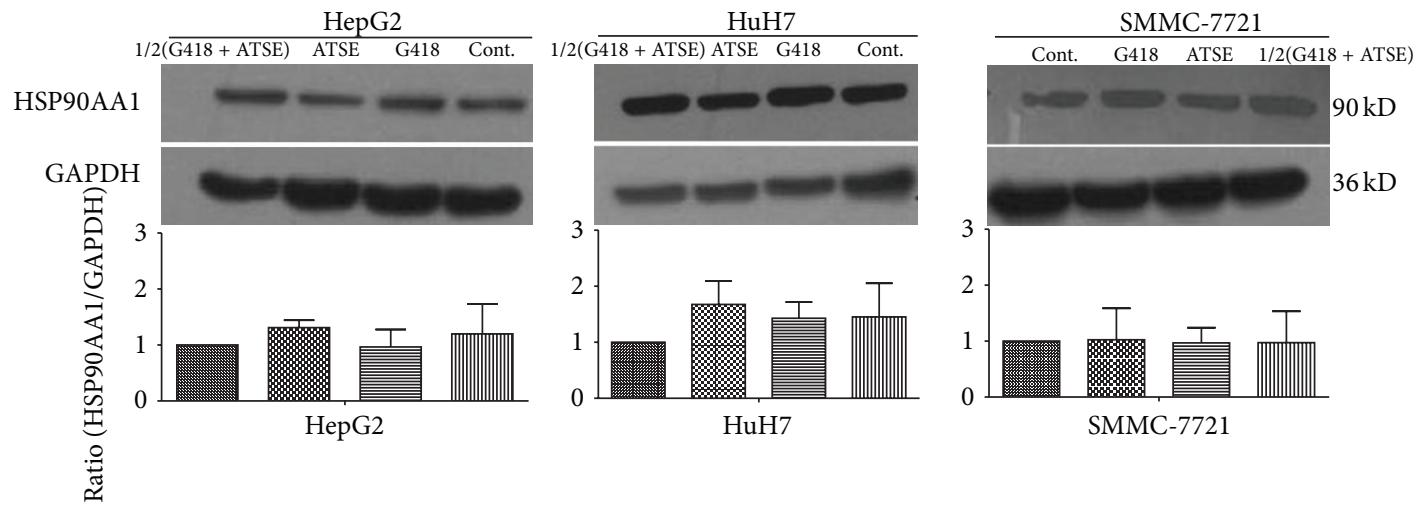

(b)
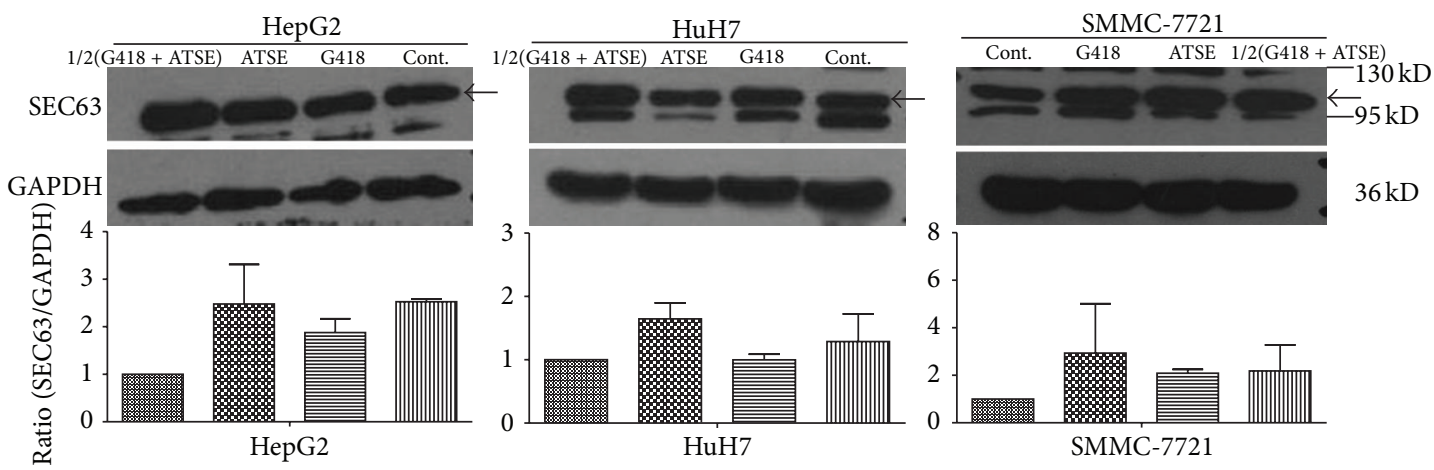

(c)
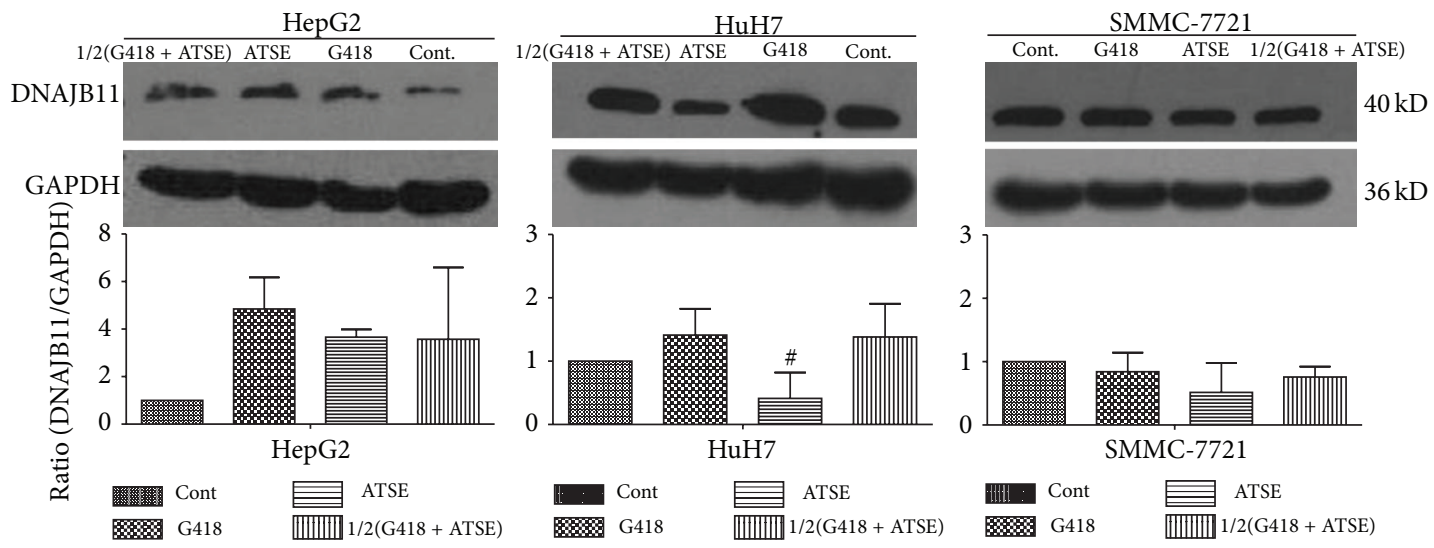

(d)

Figure 4: Continued. 

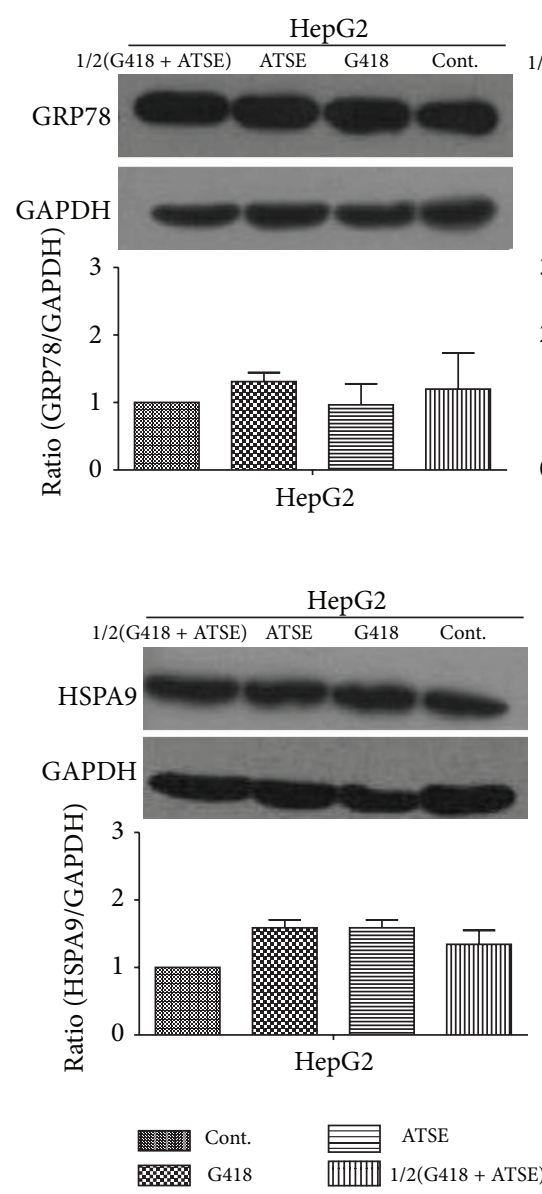

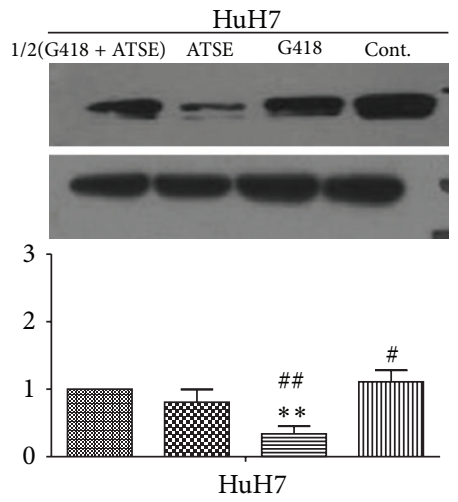

(e)
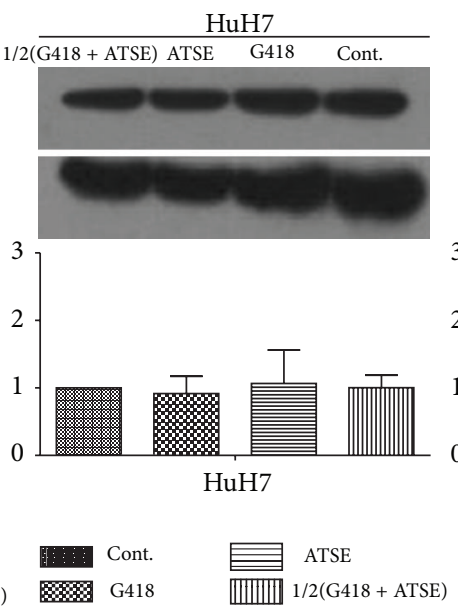
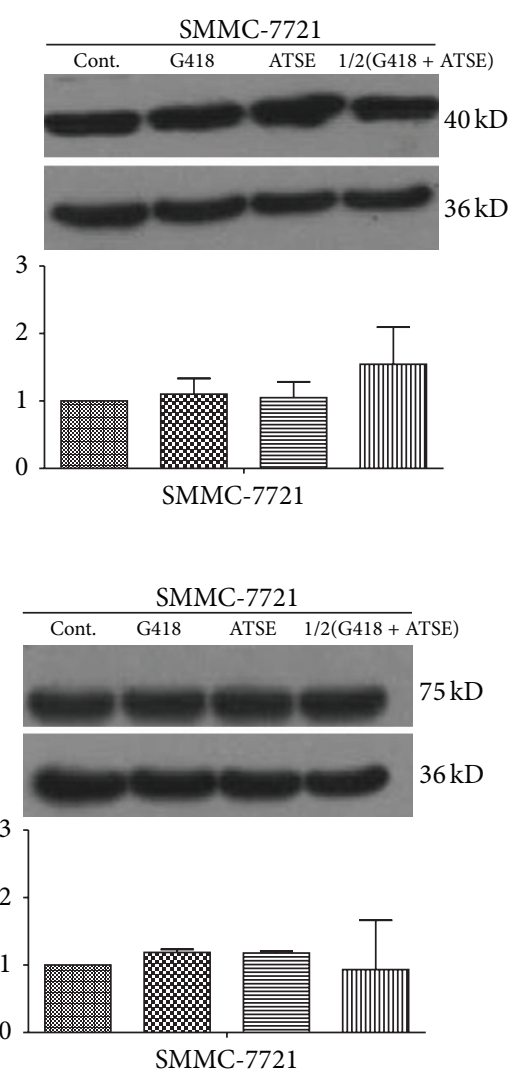

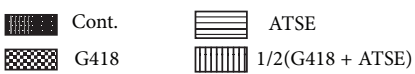

(f)

FIGURE 4: Effect of ATSE on the protein expression of ER stress-related biomarkers. The relative expression of ER-stress biomarkers at protein level after 72-hour treatment. GAPDH was used as internal control. G418 $(0.45 \mathrm{mg} / \mathrm{mL})$; ATSE: Akebia trifoliate seed extract $(0.625 \mathrm{mg} / \mathrm{mL})$; 1/2(G418 + ATSE): a combination of half dosage of each accordingly. (a) relative protein expression of HYOU1, (b) relative protein expression of HSP90AA1, (c) relative protein expression of SEC63, (d) relative expression of DNAJB11, (e) relative protein expression of GRP78, and (f) relative protein expression of HSPA9. The values given are the mean \pm S.D. $(n=3)$; ${ }^{* *} P<0.01$ and ${ }^{*} P<0.05$ (versus control group); ${ }^{\# \#} P<0.01$ and ${ }^{\#} P<0.05$ (versus G418 group).

the other hand, compared with G418, most of the proteins expressions in response to ATSE indicated a reduced trend, and HYOU1, GRP78, and DNAJB11 were reduced notably in $\mathrm{HuH7}$ (Figures 4(a), 4(d), and 4(e)).

3.5. Expression of ER Stress-Related Genes in HepG2 Cells. For full characterization of the molecular mechanism of ATSE, Affymetrix array was used. 82 ER stress-related genes were selected one by one manually from NCBI gene database. There were significant changes in the levels of gene expression in 8 of 82 genes (Table 1); HSP90AA1 was included and upregulated by ATSE significantly.

3.6. Expression of ER Stress-Related Genes in HuH7 Cells. There were significant changes in the levels of gene expression in 38 of 82 genes (Table 2); HSP90AA1 was included and upregulated by ATSE significantly. On the other hand, HSPA9,
DNAJB11, SEC63, HYOU1, and GRP78 were all downregulated notably. Furthermore, most of the genes were downregulated.

3.7. Expression of ER Stress-Related Genes in SMMC-7721 Cells. There were significant changes in the levels of gene expression in 19 of 82 genes (Table 3). SEC63, DNAJB11, HSP90AA1, and GRP78 were all downregulated notably. It is similar to $\mathrm{HuH7}$ that most of the genes were downregulated notably.

3.8. Expression of the KEGG Integrin-Mediated Cell Adhesion Pathway for HepG2 Cells. Affymetrix array data also presented genes expressions information of KEGG integrinmediated cell adhesion pathway, which helps to explain the effect of ATSE on HepG 2 cells. There were significant changes in 6 of 89 genes, 4 were upregulated and 2 were downregulated (Table 4). 
TABLE 1: List of ER stress-related genes with significant expression in HepG2 cells (fold change $\geq 1.5$-fold).

\begin{tabular}{|c|c|c|c|c|c|c|}
\hline Probe set ID & Gene symbol & Control & G418 & ATSE & 1/2(G418 + ATSE) & ATSE/control \\
\hline 8152628 & DERL1 & 199 & 336 & 355 & 694 & 1.78 \\
\hline 7954196 & MGST1 & 733 & 958 & 1305 & 1663 & 1.78 \\
\hline 7995895 & HERPUD1 & 714 & 1239 & 1166 & 2351 & 1.63 \\
\hline 7981335 & HSP90AA1 & 1263 & 2402 & 1946 & 3732 & 1.54 \\
\hline 7956593 & OS9 & 315 & 357 & 475 & 407 & 1.51 \\
\hline 8156838 & SEC61B & 528 & 426 & 348 & 631 & -1.52 \\
\hline 8080084 & MANF & 495 & 587 & 320 & 791 & -1.55 \\
\hline 8075182 & XBP1 & 758 & 583 & 352 & 343 & -2.16 \\
\hline
\end{tabular}

G418 (0.45 mg/mL); ATSE: Akebia trifoliate seed extract $(0.625 \mathrm{mg} / \mathrm{mL}) ; 1 / 2(\mathrm{G} 418$ + ATSE): a combination of half dose of each accordingly.

TABLE 2: List of ER stress-related genes with significant expression in HuH7 cells (fold change $\geq 1.5$-fold).

\begin{tabular}{|c|c|c|c|c|c|c|}
\hline Probe set ID & Gene symbol & Control & G418 & ATSE & 1/2(G418 + ATSE) & ATSE/control \\
\hline 7954196 & MGST1 & 479 & 815 & 1026 & 720 & 2.14 \\
\hline 8024754 & CREB3L3 & 171 & 55 & 353 & 69 & 2.06 \\
\hline 7967563 & $\mathrm{UBC}$ & 2502 & 4281 & 4550 & 7132 & 1.82 \\
\hline 7981335 & HSP90AA1 & 1153 & 3916 & 1725 & 3257 & 1.50 \\
\hline 8114455 & HSPA9 & 1116 & 1499 & 749 & 1115 & -1.50 \\
\hline 7949383 & SYVN1 & 326 & 235 & 208 & 224 & -1.57 \\
\hline 7964460 & DDIT3 & 239 & 137 & 151 & 332 & -1.58 \\
\hline 8125295 & ATF6B & 202 & 49 & 117 & 82 & -1.73 \\
\hline 8080084 & MANF & 268 & 490 & 152 & 351 & -1.77 \\
\hline 8075182 & XBP1 & 820 & 705 & 448 & 596 & -1.83 \\
\hline 8091458 & SERP1 & 561 & 1050 & 303 & 635 & -1.85 \\
\hline 8137526 & INSIG1 & 214 & 356 & 114 & 290 & -1.88 \\
\hline 7916432 & DHCR24 & 2595 & 560 & 1278 & 280 & -2.03 \\
\hline 8138108 & KDELR2 & 1272 & 1329 & 622 & 605 & -2.04 \\
\hline 8160914 & VCP & 423 & 764 & 200 & 227 & -2.11 \\
\hline 7989619 & PPIB & 1939 & 2258 & 917 & 2377 & -2.11 \\
\hline 8066889 & STAU1 & 398 & 248 & 187 & 98 & -2.12 \\
\hline 8128111 & UBE2J1 & 474 & 344 & 199 & 183 & -2.38 \\
\hline 7916120 & TXNDC12 & 817 & 404 & 330 & 172 & -2.48 \\
\hline 7958644 & ATP2A2 & 492 & 570 & 186 & 206 & -2.65 \\
\hline 8026106 & CALR & 1329 & 1694 & 497 & 1060 & -2.67 \\
\hline 8051998 & MCFD2 & 411 & 507 & 149 & 213 & -2.76 \\
\hline 7995895 & HERPUD1 & 915 & 870 & 297 & 960 & -3.08 \\
\hline 8084634 & DNAJB11 & 279 & 947 & 89 & 529 & -3.14 \\
\hline 7906819 & ATF6 & 268 & 361 & 80 & 174 & -3.33 \\
\hline 8041967 & ERLEC1 & 275 & 363 & 77 & 109 & -3.57 \\
\hline 8128650 & SEC63 & 982 & 1218 & 265 & 504 & -3.71 \\
\hline 8135480 & DNAJB9 & 256 & 431 & 53 & 351 & -4.86 \\
\hline 7952145 & HYOU1 & 492 & 757 & 97 & 266 & -5.06 \\
\hline 7956593 & OS9 & 1008 & 857 & 195 & 383 & -5.17 \\
\hline 8046759 & DNAJC10 & 452 & 202 & 77 & 27 & -5.87 \\
\hline 8023561 & LMAN1 & 941 & 1298 & 159 & 448 & -5.93 \\
\hline 7980547 & SEL1L & 333 & 295 & 46 & 68 & -7.27 \\
\hline 8164165 & GRP78 & 1834 & 2581 & 241 & 1442 & -7.62 \\
\hline 7904881 & PDIA3P & 1192 & 1261 & 131 & 644 & -9.11 \\
\hline 7958130 & HSP90B1 & 1813 & 2793 & 198 & 1396 & -9.17 \\
\hline 7983274 & PDIA3 & 1181 & 1226 & 119 & 602 & -9.95 \\
\hline 8095628 & ALB & 3131 & 1860 & 63 & 435 & -49.59 \\
\hline
\end{tabular}

G418 (0.45 mg/mL); ATSE: Akebia trifoliate seed extract $(0.625 \mathrm{mg} / \mathrm{mL}) ; 1 / 2(\mathrm{G} 418+$ ATSE): a combination of half dose of each accordingly. 
TABLE 3: List of ER stress-related genes with significant expression in SMMC-7721 cells (fold change $\geq 1.5$-fold).

\begin{tabular}{|c|c|c|c|c|c|c|}
\hline Probe set ID & Gene symbol & Control & G418 & ATSE & 1/2(G418 + ATSE) & ATSE/control \\
\hline 7964460 & DDIT3 & 106 & 274 & 525 & 546 & 4.94 \\
\hline 8076481 & CYB5R3 & 262 & 209 & 539 & 279 & 2.06 \\
\hline 8139003 & HERPUD2 & 186 & 263 & 323 & 271 & 1.74 \\
\hline 8042107 & VRK2 & 536 & 973 & 884 & 1075 & 1.65 \\
\hline 8156838 & SEC61B & 299 & 566 & 469 & 638 & 1.57 \\
\hline 8128650 & SEC63 & 776 & 954 & 522 & 653 & -1.50 \\
\hline 8062174 & ERGIC3 & 984 & 1042 & 662 & 686 & -1.50 \\
\hline 7958644 & ATP2A2 & 575 & 769 & 382 & 536 & -1.50 \\
\hline 7989619 & PPIB & 1595 & 2090 & 989 & 2036 & -1.61 \\
\hline 8084634 & DNAJB11 & 323 & 442 & 196 & 535 & -1.62 \\
\hline 7981335 & HSP90AA1 & 1428 & 2906 & 831 & 2147 & -1.72 \\
\hline 8178498 & HLA-B & 327 & 268 & 190 & 246 & -1.72 \\
\hline 7958130 & HSP90B1 & 1426 & 2138 & 744 & 2022 & -1.92 \\
\hline 8091954 & GOLIM4 & 641 & 378 & 329 & 364 & -1.95 \\
\hline 7983274 & PDIA3 & 855 & 1271 & 437 & 949 & -1.96 \\
\hline 8023561 & LMAN1 & 735 & 816 & 372 & 690 & -1.98 \\
\hline 7904881 & PDIA3P & 889 & 1360 & 440 & 980 & -2.02 \\
\hline 8164165 & GRP78 & 1317 & 2308 & 580 & 2346 & -2.27 \\
\hline 8160914 & VCP & 333 & 318 & 114 & 278 & -2.91 \\
\hline
\end{tabular}

G418 (0.45 mg/mL); ATSE: Akebia trifoliate seed extract $(0.625 \mathrm{mg} / \mathrm{mL}) ; 1 / 2(\mathrm{G} 418+$ ATSE): a combination of half dose of each accordingly.

TABLE 4: List of genes with significant expression in the KEGG integrin-mediated cell adhesion pathway for HepG2 cells (fold change $\geq 1.5$ fold).

\begin{tabular}{|c|c|c|c|c|c|c|}
\hline Probe set ID & Gene symbol & Control & G418 & ATSE & $1 / 2(\mathrm{G} 418+$ ATSE $)$ & ATSE/control \\
\hline 7983763 & MAPK6 & 233 & 314 & 382 & 405 & 1.64 \\
\hline 8046380 & ITGA6 & 216 & 323 & 385 & 220 & 1.78 \\
\hline 8051670 & SOS1 & 291 & 386 & 520 & 515 & 1.79 \\
\hline 8084963 & PAK2 & 173 & 252 & 360 & 338 & 2.08 \\
\hline 8090162 & ITGB5 & 330 & 357 & 220 & 150 & -1.50 \\
\hline 8111915 & SEPP1 & 3337 & 2847 & 1761 & 1131 & -1.87 \\
\hline
\end{tabular}

G418 (0.45 mg/mL); ATSE: Akebia trifoliate seed extract $(0.625 \mathrm{mg} / \mathrm{mL}) ; 1 / 2(\mathrm{G} 418+$ ATSE): a combination of half dose of each accordingly.

3.9. Expression of the KEGG Apoptosis Pathway for $\mathrm{HuH7}$ Cells. 89 genes in the KEGG apoptosis pathway were displayed in Affymetrix array data. There were significant changes in the levels of gene expression in 6 of 89 genes, 5 were upregulated and 1 was downregulated (Table 5).

\section{Discussion}

Akebia Fructus has been long used for HCC in TCM in China, in the manner of one member in herbal formula under most circumstances. The data from clinical epidemiological investigation on $2060 \mathrm{HCC}$ cases [19], and retrospective analysis on the published papers containing the use of herbal formulas for HCC, indicated that the frequency for Akebiae Fructus is up to nearly $43 \%$ [20], which means that Akebiae Fructus is popular in herbal formula and plays an important role and also means that it is worthwhile to reveal the underlying molecular mechanism of how this herb works and a possibility of a new anticancer agent.
Therefore, in our recently work [14-18], we chose Akebia trifoliate (Thunb.) Koidz, one of the three medicinal species in China, to carry out research. Considering Akebia Fructus is always used as a whole fruit, we separated the fruit into two parts, the pulp and the seed, to observe the effect on SMMC-7721 cells, and the result was beyond expectation. We found that Akebia trifoliate seed extract (ATSE) could suppress the proliferation and caused notable ER stress in SMMC-7721 cells, which suggested ATSE could inhibit proliferation and probably via inducing ER stress. To further investigate this phenomenon, HepG2, HuH7, and SMMC7721 cells were used and the dose of ATSE was according to our previous work [14-18]. In view of G418 being a commonly used cytotoxic antibiotic that can suppress proliferation of many cancer cells and presumable advantages of combined therapy, G418 and combination groups were also set up. The combination group is composed of half doses of each.

Our data exhibited that ATSE leads to different degrees of ER stress in these HCC cell lines and a decrease in cell 
TABLE 5: List of genes with significant expression in the KEGG-apoptosis pathway for HuH7 cells (fold change $\geq 1.5$-fold).

\begin{tabular}{|c|c|c|c|c|c|c|}
\hline Probe set ID & Gene symbol & Control & G418 & ATSE & 1/2(G418 + ATSE) & ATSE/control \\
\hline 8149733 & TNFRSF10B & 408 & 688 & 794 & 805 & 1.95 \\
\hline 7966746 & HRK & 153 & 188 & 252 & 403 & 1.65 \\
\hline 8065569 & BCL2L1 & 1172 & 1558 & 1822 & 1293 & 1.55 \\
\hline 8012257 & TP53 & 212 & 209 & 320 & 66 & 1.51 \\
\hline 7956989 & MDM2 & 766 & 1242 & 1138 & 680 & 1.50 \\
\hline 7924733 & PARP1 & 102 & 90 & 67 & 56 & -1.50 \\
\hline
\end{tabular}

G418 (0.45 mg/mL); ATSE: Akebia trifoliate seed extract $(0.625 \mathrm{mg} / \mathrm{mL}) ; 1 / 2(\mathrm{G} 418+$ ATSE): a combination of half dose of each accordingly.

viability (Figures 1 and 2). In fact, a lot of previous work has been done to investigate the herbal medicine on HCC, and several mechanisms of action have been clarified [4], such as cytotoxic activities against cancer cell lines [21, 22], while the effect that related ER stress to HCC cells was relatively rarely mentioned. On the other hand, the endoplasmic reticulum has been posited as a potential anticancer target [23]. Indeed some anticancer chemotherapeutic agents have been shown to induce ER stress, such as the proteasome inhibitor bortezomib [24], as well as the cannabinoids [25]. However, most of these kinds of research did not provide visual morphological evidence of ER stress, while our data was presented intuitively and suggested that SMMC-7721 is the most sensitive in terms of morphology (Figure 1).

As shown in Figure 3, the cell cycle analysis by FCM was performed to find out the relevance of cell cycle and proliferation inhibition. Basically, not so many notable changes in statistical data were observed. On the other hand, in contrast to the uncertain cell cycle alteration, other information, just like cells which behaved differently in response to ATSE, cannot be ignored. Firstly, in HepG2 cells, a continuous peak can be seen after the G2/M phase (Figure 3(a)) and it seemed that the amount of peak was reduced by ATSE (Figure 3(c)), implying that ATSE may reduce the adhesion between HepG2 cells, which is meaningful for fewer tumor metastases. This speculation was based on the following: contact inhibition does not happen to HepG2, so cells could grow overlapped. It is difficult to separate cells to a single one in vitro, which is distinguished from the other two kinds. Therefore, when the PI stained HepG2 cells pass through FCM, the continuous peak after G2/M phase formed. Another reference is gene expression in the integrin-mediated cell adhesion pathway (Table 4). Further experiments such as the cell adhesion assay can be considered. Secondly, unlike the other two kinds, HuH7 cells proliferate very quickly. Apoptosis occurs spontaneously in the absence of ATSE (Figure 3(e)) and intensified in the presence of ATSE (Figure 3(g)). Thus, ER stress-mediated apoptosis is possibly involved; many genes expressions in the apoptosis pathway are upregulated by ATSE as well (Table 5). All these data reveal that the distinction exists in ATSE against different HCC cells. In addition, cell cycle regulatory proteins can be considered in further research.

Besides morphological changes and cell cycle alterations, ER stress is often accompanied with expression changes of a lot of genes and proteins, or called as biomarkers. Generally, this event started from three transmembrane sensors in UPR (unfolded protein response) pathway [26, 27], namely, ATF6, IRE1, and PERK, and a lot of downstream molecules, such as Grp78 and DDIT3. Some effective ingredients from herb, such as Tanshinone IIA, have shown the effect of induction of ER stress on prostate cancer cells, and increased expression of Grp78 was identified [28]. ER stress was activated by Tubeimoside-1, a triterpenoid saponin extracted from Bolbostemma paniculatum, with an increased expression of DDIT3 in human cervical carcinoma cells [29], while our previous data indicated that ATSE selectively suppressed mRNA expression of many ER stress-related genes in SMMC-7721 cells, especially of Hyou1, Hsp90aa1, Sec63, Dnajb11, Grp78, and Hspa9. To understand more about this, further proteins expressions were monitored by WB, genes' profiles were assessed by Affeymetrix array as well and more cell lines were used besides SMMC-7721. First, in HepG2 and SMMC-7721 cells, ATSE led to an increased trend of these chosen proteins versus control, but not significantly, while in $\mathrm{HuH7}$ cells, Hyoul and Grp78 were notably downregulated (Figure 4). Secondly, a lot of genes showed significant changes versus control, and downward is the main trend (Tables 1, 2, and 3). As to the six selected genes, only HSP90AA1 was upregulated In HepG2 and $\mathrm{HuH7}$, and the others were all downregulated in all cell lines. Combining the expression feature of proteins and genes, one relatively reasonable explanation is that the alteration in the ER stress event depends on cell's status, as many factors could induce ER stress, and degree varies. When cells are under adaptation circumstances, UPR pathway works and a lot of molecules were mobilized and against stress successfully, such as Grp78 which helps to maintain ER integrity. However, if stress is beyond cells' tolerance or stress continues, apoptosis will be one possible outlet and several molecules such as DDIT3 will be designated to mediate this process $[27,30]$, and subsequently more molecules will take part in the event or quit, which make the situation complex.

Furthermore, even Affeymetrix array presented such a comprehensive gene expression profile; how ER stress was induced and how these genes or proteins are influenced by ATSE, active or passive, directly or indirectly remain unclear. Therefore, besides the continued analysis of these data, further investigations, such as cotreatment with some mechanism-known ER-stress-induced agents and such as 
genes knocked down by RNA interference, are beneficial to know more about how ATSE works and the role of those significantly changed genes or proteins.

The phytochemistry of ATSE is not discussed in the present work, for the main ingredients are almost clear, which are triterpenoid saponins. Since the work of Ryuichi et al. in the last century [31, 32], there are around 90 triterpenoid saponins which have been discovered in Akebia Decne so far [33, 34], including Akebia trifoliate (Thunb.) Koidz and other medicinal species; medicinal parts involve fruit, seed, stem root, and other sections. However, it remains important to further characterize new biological activities of known ingredients.

The effect of drug combination is also worthy of attention. As shown in the MTT result (Figure 2), the cell viability of the combination group decreased significantly compared to the control, which was consistent in all cell lines, and the level was lower than G418 and the ATSE group in HepG2 cells as well as the apoptotic body peak before G0/G1 phase responded to this (Figure 3(d)). Overall though, we speculate that if ATSE combined with a cytotoxic antibiotic, it would make sense to affect a dosage reduction of cytotoxic antibiotics or herb preparation, for therapeutic efficacy to improve, for side effects to be reduced, and to create more opportunities for patients suffering from cancer.

In summary, our data demonstrated that the Akebia trifoliate (Thunb.) Koidz seed extract (ATSE) has a certain effect on proliferation inhibition in HepG2, HuH7, and SMMC7721 cell lines and ER stress induction involved. It provides a promising candidate therapeutic agent anti-HCC, and further studies are required.

\section{Abbreviations}

ATSE: Akebia trifoliate seed extract

HCC: Human hepatocellular carcinoma

TCM: Traditional Chinese medicine

MTT: 3-(4, 5-Dimethylthiazol-2-yl)-2, 5-diphenyltetrazolium bromide

ER: Endoplasmic reticulum

KEGG: Kyoto Encyclopedia of Genes and Genomes.

\section{Conflict of Interests}

The authors declare that there is no conflict of interests regarding the publication of this paper.

\section{Authors' Contribution}

Wen-Li Lu and Hong-Yan Ren contributed equally to this work.

\section{Acknowledgment}

This work was supported by the National Natural Science Foundation of China (no. 30973703 and no. 81273641).

\section{References}

[1] A. P. Venook, C. Papandreou, J. Furuse, and L. L. de Guevara, "The incidence and epidemiology of hepatocellular carcinoma: a global and regional perspective," The Oncologist, vol. 15, no. 4, pp. 5-13, 2010.

[2] World Health Organization, Liver cancer estimated incidence, mortality and prevalence worldwide in 2012, http://globocan.iarc.fr/Pages/fact_sheets_cancer.aspx.

[3] S. Mondal, S. Bandyopadhyay, M. K. Ghosh, S. Mukhopadhyay, S. Roy, and C. Mandal, "Natural products: Promising resources for cancer drug discovery," Anti-Cancer Agents in Medicinal Chemistry, vol. 12, no. 1, pp. 49-75, 2012.

[4] Y. Li and R. C. G. Martin, "Herbal medicine and hepatocellular carcinoma: applications and challenges," Evidence-based Complementary and Alternative Medicine, vol. 2011, Article ID 541209, 14 pages, 2011.

[5] P. Wu, J. J. Dugoua, O. Eyawo, and E. J. Mills, "Traditional Chinese medicines in the treatment of hepatocellular cancers: a systematic review and meta-analysis," Journal of Experimental and Clinical Cancer Research, vol. 28, no. 1, article 112, 2009.

[6] M. C. Wu, "Traditional Chinese medicine in prevention and treatment of liver cancer: function, status and existed problems," Journal of Chinese Integrative Medicine, vol. 1, no. 3, pp. 163-168, 2003.

[7] F. H. Qi, A. Y. Li, Y. Inagaki et al., "Chinese herbal medicines as adjuvant treatment during chemoor radio-therapy for cancer," BioScience Trends, vol. 4, no. 6, pp. 297-307, 2010.

[8] L. Li, X. H. Yao, C. H. Zhong, X. Z. Chen, and H. Huang, "Akebia: a potential new fruit crop in China," HortScience, vol. 45, no. 1, pp. 4-10, 2010.

[9] Chinese Pharmacopoeia Commission, China Pharmacopeia, China Medical Science Press, Beijing, China, 2010.

[10] B. W. Qian, Application of Anti-Cancer Chinese Medicine, Shanghai Translation Publishing House, Shanghai, China, 1987.

[11] H. S. Kang, J. S. Kang, and W. S. Jeong, "Cytotoxic and apoptotic effects of saponins from akebia quinata on HepG2 Hepatocarcinoma cells," Korean Journal of Food Preservation, vol. 17, no. 3, pp. 311-319, 2010.

[12] H. J. Jung, C. O. Lee, K. T. Lee, J. Choi, and H. J. Park, "Structureactivity relationship of oleanane disaccharides isolated from Akebia quinata versus cytotoxicity against cancer cells and NO inhibition," Biological and Pharmaceutical Bulletin, vol. 27, no. 5, pp. 744-747, 2004.

[13] H. Sun, W.-S. Fang, W.-Z. Wang, and C. Hu, "Structure-activity relationships of oleanane- and ursane-type triterpenoids," Botanical Studies, vol. 47, no. 4, pp. 339-368, 2006.

[14] Z. Q. Fang, H. Y. Ren, C. Liang et al., "One kind of predictable Akebia Fructus extract in the treatment of primary liver cancer," Chinese Patent CN103191161A, 2013.

[15] Z. Q. Fang, H. Y. Ren, C. Liang et al., "One kind of predictable Akebia Fructus seed extract in the treatment of primary liver cancer," Chinese Patent CN103191162A, 2013.

[16] Z. Q. Fang, H. Y. Ren, C. Liang et al., "Akebia Fructus seed extractive and cytotoxin antibiotic combined composition and application," Chinese Patent CN103191428A, 2013.

[17] Z. Q. Fang, H. Y. Ren, C. Liang et al., "The mechanism of Akebia trifoliate seed inhibits the proliferation of liver cancer cell lines," in Proceedings of the 9th Annual Meeting of the Basic Theory of Integrated Traditional and Western Medicine, pp. 345-349, 2013. 
[18] Z. Q. Fang, H. Y. Ren, C. Liang et al., “The mechanism research on the proliferation inhibition by the common used herbal compound," Chinese Journal of Basic Medicine in Traditional Chinese Medicine, vol. 19, no. 1, pp. 34-37, 2013.

[19] Y. J. Li, Z. Q. Fang, C. L. Tang et al., "Clinical epidemiological investigation and research of syndrome distribution law in chinese medicine of 2060 cases of primary liver carcinoma," Chinese Medical Journal, vol. 18, no. 3, pp. 144-147, 2003.

[20] D. S. Chen and Z. Q. Fang, "Analysis on the frequency of herbs used in primary hepatocellular carcinoma," Liaoning Journal of Traditional Chinese Medicine, vol. 29, no. 4, pp. 187-189, 2002.

[21] W. Zhang, J. G. Luo, C. Zhang, and L. Y. Kong, "Different apoptotic effects of triterpenoid saponin-rich Gypsophila oldhamiana root extract on human hepatoma SMMC-7721 and normal human hepatic L02 cells," Biological and Pharmaceutical Bulletin, vol. 36, no. 7, pp. 1080-1087, 2013.

[22] I. Podolak, A. Galanty, and D. Sobolewska, "Saponins as cytotoxic agents: a review," Phytochemistry Reviews, vol. 9, no. 3, pp. 425-474, 2010.

[23] T. Nieto-Miguel, R. I. Fonteriz, L. Vay, C. Gajate, S. LópezHernández, and F. Mollinedo, "Endoplasmic reticulum stress in the proapoptotic action of edelfosine in solid tumor cells," Cancer Research, vol. 67, no. 21, pp. 10368-10378, 2007.

[24] A. Fribley, Q. Zeng, and C.-Y. Wang, "Proteasome inhibitor PS-341 induces apoptosis through induction of endoplasmic reticulum stress-reactive oxygen species in head and neck squamous cell carcinoma cells," Molecular and Cellular Biology, vol. 24, no. 22, pp. 9695-9704, 2004.

[25] A. Carracedo, M. Gironella, M. Lorente et al., "Cannabinoids induce apoptosis of pancreatic tumor cells via endoplasmic reticulum stress-related genes," Cancer Research, vol. 66, no. 13, pp. 6748-6755, 2006.

[26] M. J. Berridge, "The endoplasmic reticulum: a multifunctional signaling organelle," Cell Calcium, vol. 32, no. 5-6, pp. 235-249, 2002.

[27] D. Ron and P. Walter, "Signal integration in the endoplasmic reticulum unfolded protein response," Nature Reviews Molecular Cell Biology, vol. 8, no. 7, pp. 519-529, 2007.

[28] S. C. Chiu, S. Y. Huang, S. P. Chen, C. C. Su, T. L. Chiu, and C. Y. Pang, "Tanshinone IIA inhibits human prostate cancer cells growth by induction of endoplasmic reticulum stress in vitro and in vivo," Prostate Cancer and Prostatic Diseases, vol. 16, no. 4, pp. 315-322, 2013.

[29] Y. Xu, J. F. Chiu, Q. Y. He, and F. Chen, "Tubeimoside-1 exerts cytotoxicity in heLa cells through mitochondrial dysfunction and endoplasmic reticulum stress pathways," Journal of Proteome Research, vol. 8, no. 3, pp. 1585-1593, 2009.

[30] G. Velasco, T. Verfaillie, M. Salazar, and P. Agostinis, "Linking ER stress to autophagy: potential implications for cancer therapy," International Journal of Cell Biology, vol. 2010, Article ID 930509, 19 pages, 2010.

[31] H. Ryuichi, K. Miyahara, and T. Kawasaki, "Seed saponins of akebia quinata dence. I. hederagenin 3-0-glycosides," Chemical and Pharmaceutical Bulletin, vol. 20, no. 9, pp. 1935-1939, 1972.

[32] H. Ryuichi, K. Miyahara, and T. Kawasaki, "Seed saponins of Akebia quinata Dence. II. Hederagenin 3,28-0-bisglycosides," Chemical and Pharmaceutical Bulletin, vol. 20, no. 10, pp. 21432149, 1972.

[33] Z. F. Li, Q. Wang, Y. T. Liu et al., "Chemical constituents from Akebia trifoliate," Chinese Journal of Traditional Medical Formulae, vol. 19, no. 21, pp. 56-60, 2013.
[34] D. Jiang, S. P. Shi, J. J. Cao, Q. P. Gao, and P. F. Tu, “Triterpene saponins from the fruits of Akebia quinata," Biochemical Systematics and Ecology, vol. 36, no. 2, pp. 138-141, 2008. 


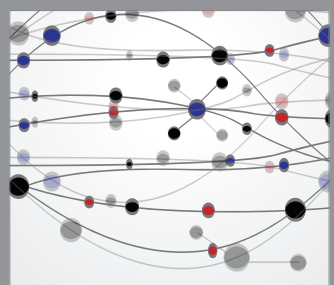

The Scientific World Journal
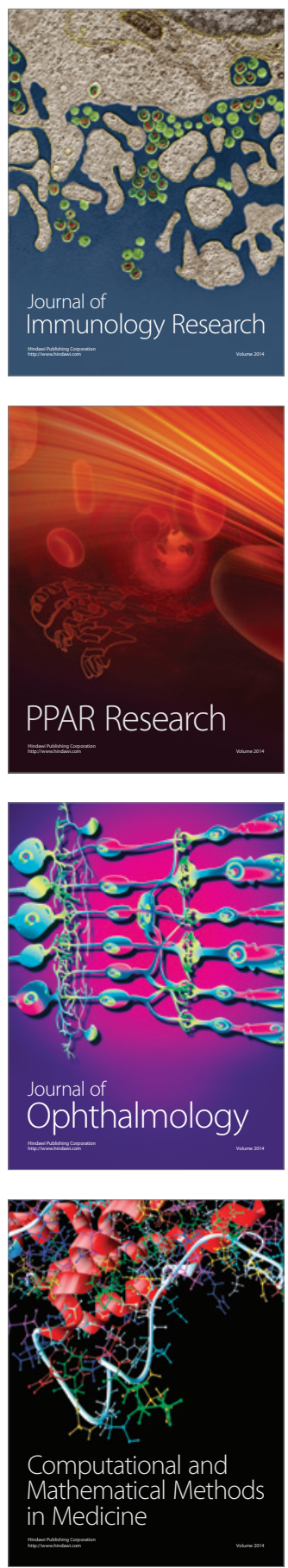

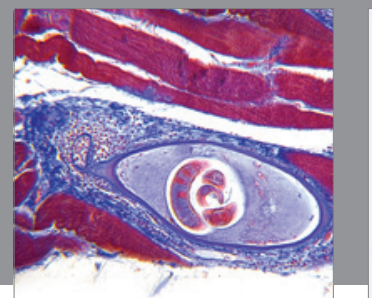

Gastroenterology

Research and Practice
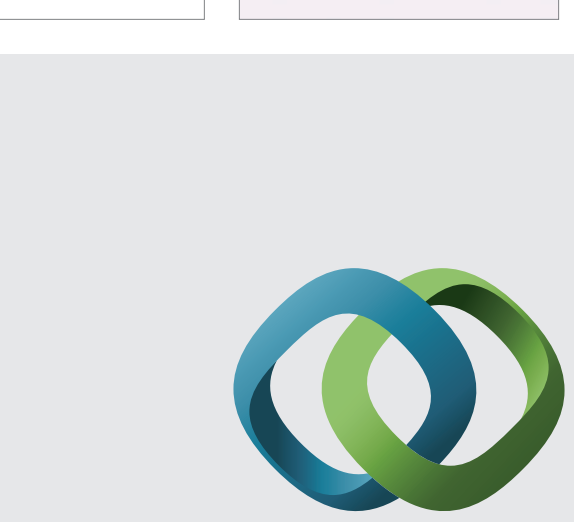

\section{Hindawi}

Submit your manuscripts at

http://www.hindawi.com
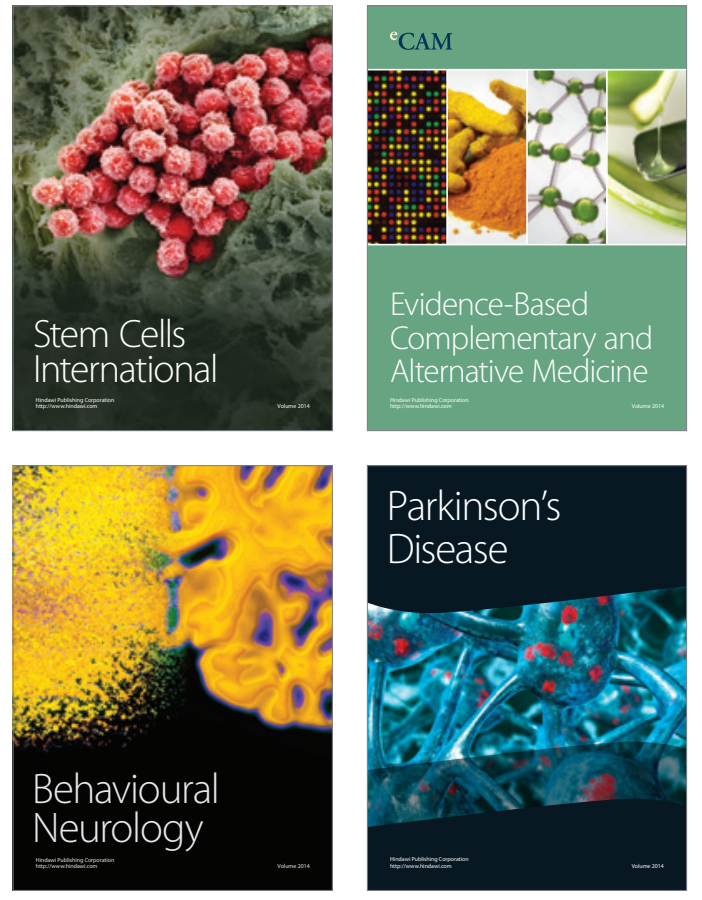
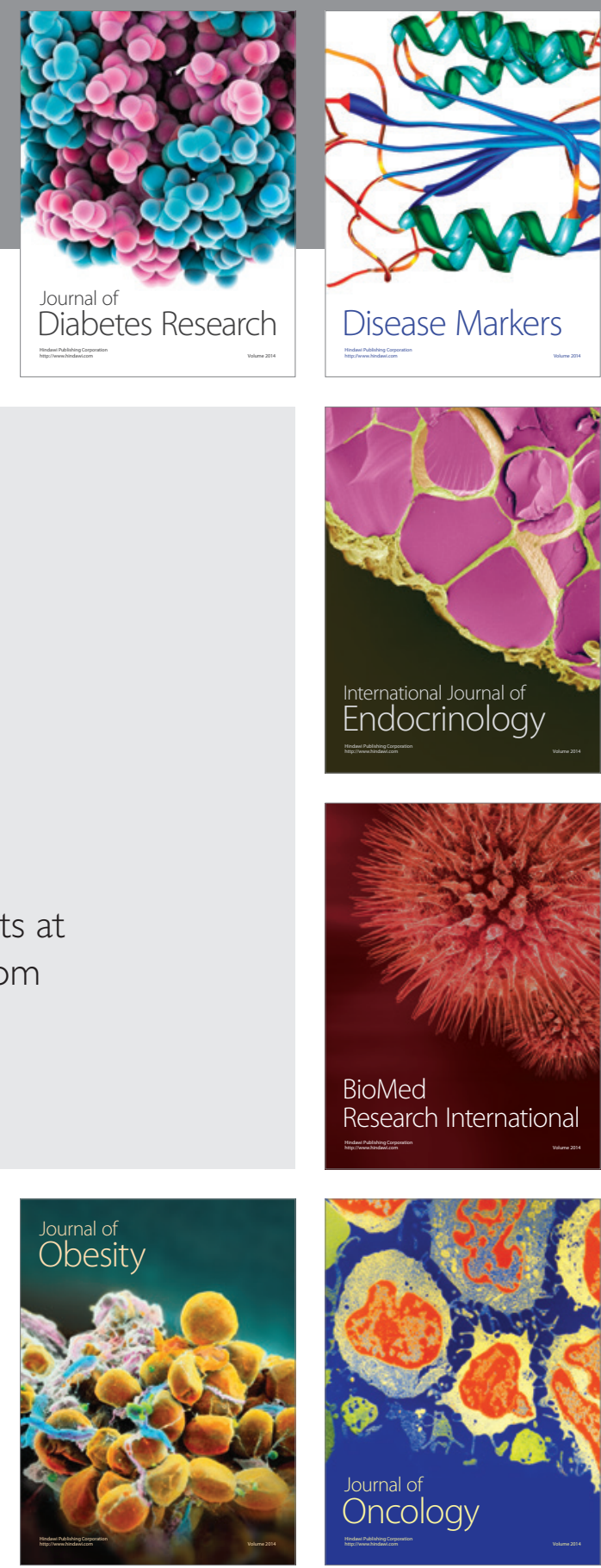

Disease Markers
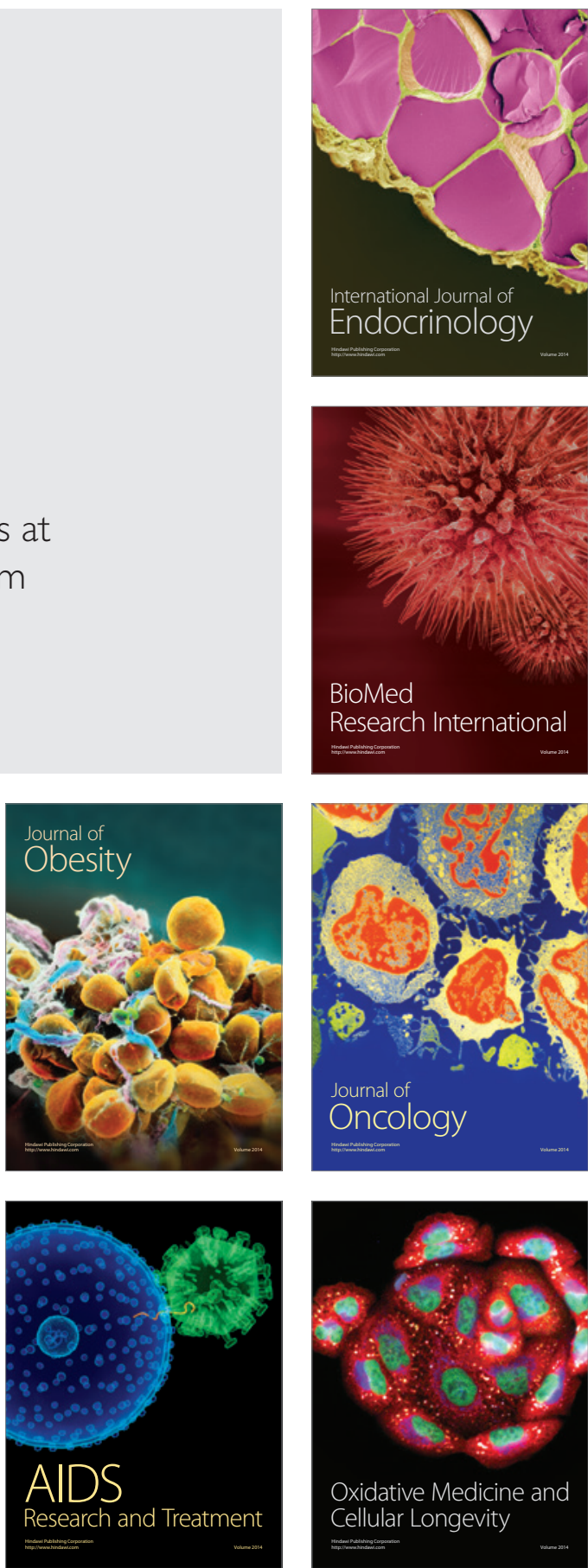